\title{
Forty-year radiological follow-up of a patient undergoing bilateral developmental dysplasia of the hip surgery: A joint with remodeling capacity
}

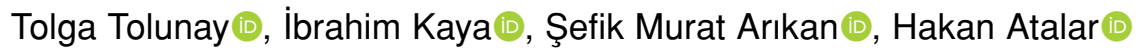 \\ Department of Orthopedics and Traumatology, Gazi University Faculty of Medicine, Ankara, Turkey
}

Developmental dysplasia of the hip (DDH) has a wide spectrum of deformities, from a mildly dysplastic hip to a severely dysplastic or fully dislocated hip. ${ }^{[1]}$ There is still little information about the exact etiopathogenesis of DDH and many genetic, mechanical and environmental risk factors are effective in its development. Although the diagnosis of DDH is usually made at an early age, there may be cases diagnosed in adolescence or adulthood. In case of late diagnosis, the probability of complications increases exponentially in the long-term. ${ }^{[2]}$

Developmental dysplasia of the hip is one of the most important causes of secondary coxarthrosis in Turkey. It alters the biomechanics of the hip, causing cartilage overload, leading to early wear of the articular cartilage and the development of

Received: January 05, 2022

Accepted: January 06, 2022

Published online: February 10, 2022

Correspondence: Tolga Tolunay, MD. Gazi Üniversitesi Tıp Fakültesi Ortopedi ve Travmatoloji Anabilim Dalı, 06560 Yenimahalle, Ankara, Türkiye.

E-mail: tolgatolunay@gazi.edu.tr

Doi: $10.52312 /$ jdrscr.2022.30

Citation: Tolunay T, Kaya I, Arıkan SM, Atalar H. Forty-year radiological follow-up of a patient undergoing bilateral developmental dysplasia of the hip surgery: A joint with remodeling capacity. Jt Dis Relat Surg Case Rep 2022;1(2):75-78.

(02022 All right reserved by the Turkish Joint Diseases Foundation

This is an open access article under the terms of the Creative Commons Attribution-NonCommercial License, which permits use, distribution and reproduction in any medium, provided the original work is properly cited and is not used for commercial purposes (http://creativecommons.org/licenses/by-nc/4.0/).

https://www.casereportsjointdrs.org

\section{ABSTRACT}

Children diagnosed with developmental dysplasia of the hip (DDH) are largely successfully treated with conservative treatment. With increasing age, associated deformities may become more complex and require increasingly aggressive treatments. A 42-year-old male patient was admitted with the complaint of pain in both hips. In his medical history, open reduction of her left hip was performed at the age of two due to DDH. Open reduction of the right hip was performed, when he was approximately 2.5 years old, and a shortening and derotation osteotomy of the right femur was performed two months later. Upon admission to our center, it was determined that the relationship between the acetabulum and femur was preserved in both hips and there was no dislocation in the 40-year follow-up radiograph. In conclusion, this case has, once again, shown that the remodeling capacity of the hip joint in childhood is high.

Keywords: Acetabulum dysplasia, concentric reduction, developmental dysplasia of the hip, remodeling capacity.

osteoarthritis (OA). It is estimated that 2.6 to $9.1 \%$ of total hip arthroplasty (THA) cases are due to OA secondary to DDH and is the main reason for THA surgery in young individuals (approximately 21 to $29 \%$ ). ${ }^{[3]}$ In pediatric DDH management, morbidity associated with this disease can be prevented to a large extent with early diagnosis and conservative treatment. Currently, hip ultrasonography scanning is performed for this purpose. Hip ultrasound is the gold-standard diagnostic, monitoring tool for $\mathrm{DDH}$ in neonates and infants less than six months old and has been adopted as a routine screening method for DDH. ${ }^{[4]}$ Children diagnosed with DDH are largely successfully treated with conservative treatment. Surgical approaches are recommended, when conservative treatments fail. With increasing age, associated deformities may become more complex and require increasingly aggressive treatments such 
as open reduction and femoral or pelvic osteotomy. ${ }^{[5]}$ In the years when ultrasonographic scanning was not known, the diagnosis of DDH was usually made after the walking age and it was attempted to be treated with surgery.

In this report, we discuss the 40-year follow-up results of a patient who underwent surgical treatment for DDH in the late 1970s.

\section{CASE REPORT}

A 42-year-old patient was referred to our clinic with the complaint of pain in both hips, which was prominent in the right hip. In his medical history, he was operated for DDH, when he was two years old. The patient who underwent open reduction of his left hip in December 1978 was hospitalized one month later (January 1979) for ipsilateral femoral derotation. However, as he had mumps, his surgery was postponed and a weight of $2 \mathrm{~kg}$ was tied and he was taken to skin traction and discharged home. In the later follow-ups, left femur shortening and derotation osteotomy was not performed, considering that the development of the hip was good. Postoperative radiographs of the left hip at six months and preoperative radiograph of the right hip (Figure 1, June 1979) showed dysplasia of the left acetabulum and dislocation of the right hip.

From the examination of the operation reports, it was learned that open reduction of the right hip was performed on June $13^{\text {th }}, 1979$, and right femur shortening and derotation osteotomy was performed two months later (August 1979). In the early postoperative follow-up X-ray, the osteotomy line was fused; however, both acetabulum dysplasias,

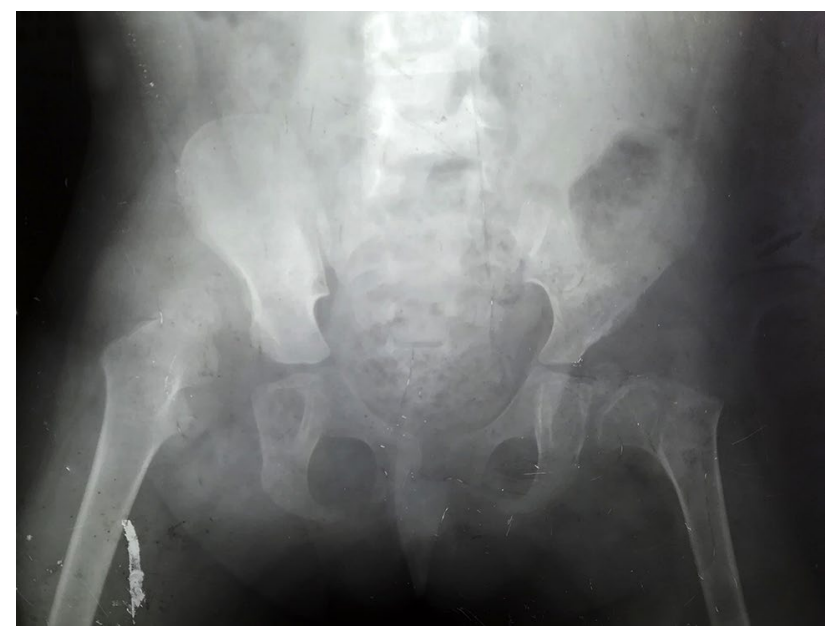

Figure 1. An anteroposterior pelvis radiograph six months after left hip open reduction. prominent on the right, continued. Acetabular index measured approximately 44 degrees in the right hip and 30 degrees in the left hip (Figure 2).

On the radiograph four years after the operation (January $6^{\text {th }}, 1983$, Figure 3), the development of both hips was good, concentric reduction was achieved and the acetabular index was approximately 22 degrees in both hips. The patient was admitted to our hospital in October 2019 with the complaint of increasing pain in both hips for four years. During examination, the movements of both hips, particularly on the right, were limited and painful. In the 40-year follow-up

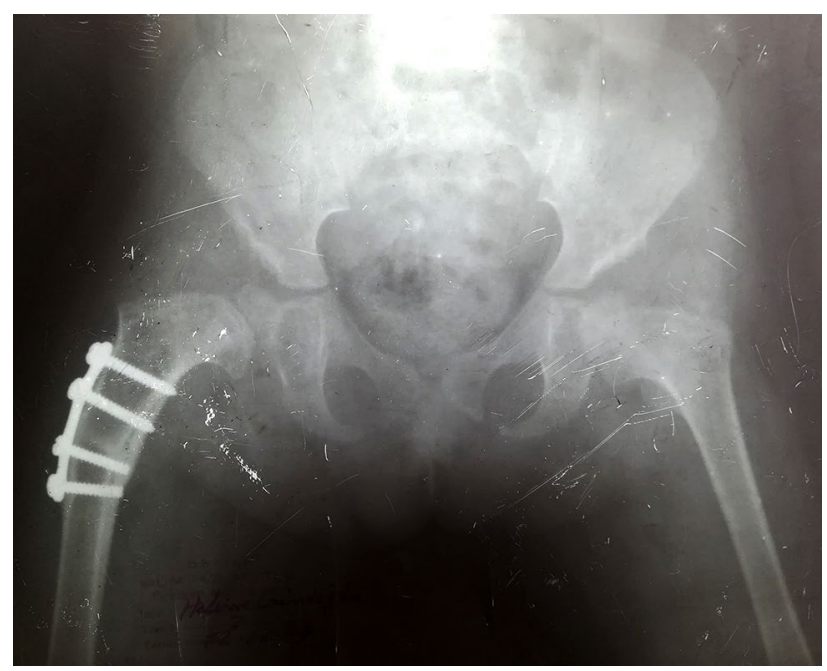

Figure 2. An image of the right hip after open reduction and femoral osteotomy. Both hips appear to have acetabular dysplasia. Acetabular index is measured approximately 44 degrees in the right hip and 30 degrees in the left hip.

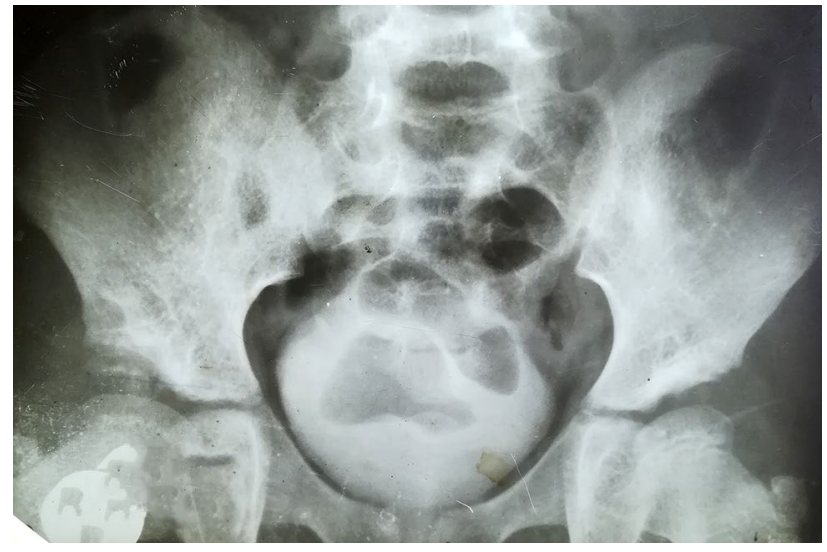

Figure 3. An anteroposterior pelvis radiograph taken on January $6^{\text {th }}, 1983$. Concentric reduction was achieved in both hips and both acetabula appear to be remodeled. Acetabular index on both hips is approximately 22 degrees. 


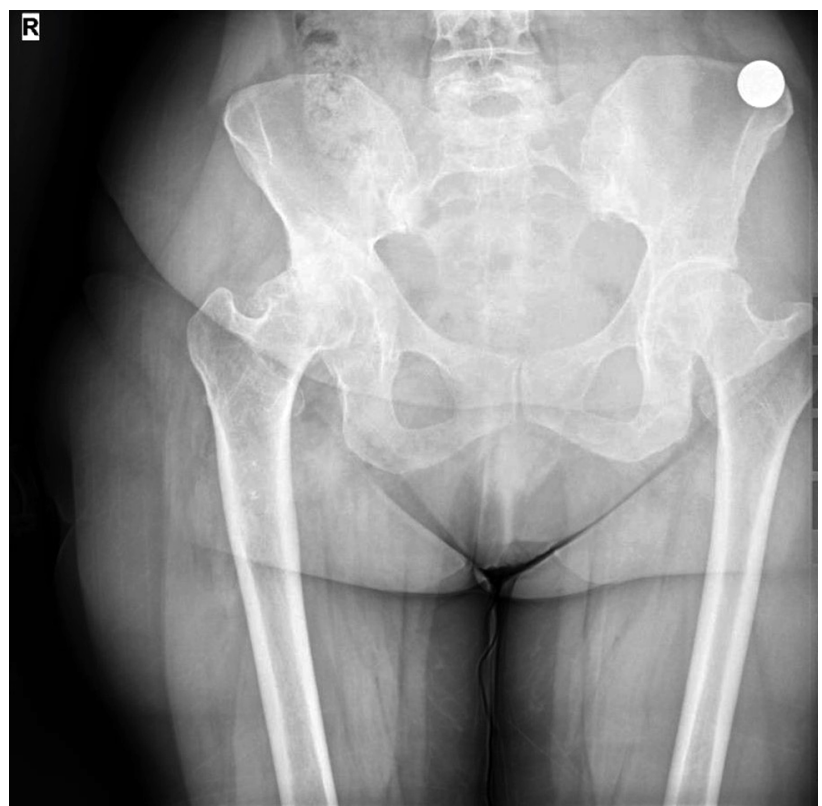

Figure 4. Concentric reduction is achieved in both hips, but arthrosis is seen in both hips, more prominently in the right hip.

radiograph (October 1 ${ }^{\text {st }}, 2019$, Figure 4), concentric reduction was achieved in both hips, but arthrosis developed in both hips, prominently on the right.

The patient was informed that data from the case would be submitted for publication and gave his consent.

\section{DISCUSSION}

The main goal of DDH treatment is to achieve and maintain concentric reduction of the hip joint. While the chance of achieving this goal is high with conservative treatment in children diagnosed before six months of age, surgery becomes inevitable to achieve concentric reduction in children diagnosed after walking age. In the surgical treatment of DDH, osteotomies are performed for the femur and pelvis, except for open reduction, and it is known that there is no standard surgical method accepted by all centers. ${ }^{[6]}$

Femoral osteotomies are designed to reorient the femoral head by increasing derotation and varus to stimulate and stabilize acetabular development. ${ }^{[7]}$ In the case we presented, open reduction on the left side, open reduction on the right side, and then femoral osteotomy were performed in separate sessions. Bilateral acetabulum dysplasia continued, with acetabulum dysplasia prominent on the right in the early periods following the surgery. In the literature, it is recommended to perform acetabular and/or femoral osteotomies in cases with persistent acetabular dysplasia to prevent or minimize the risk of coxarthrosis. ${ }^{[3]}$ Salter is of the opinion that open reduction and periacetabular osteotomy should be performed simultaneously with all treated hips in patients 18 months of age or older. ${ }^{[8]}$ On the contrary, there are studies that argue that early and routine pelvic osteotomy to correct acetabular dysplasia may be unnecessary in many children. ${ }^{[9,10]}$

The potential for remodeling of the acetabulum decreases with age and, currently, it would be usually accepted that Salter or another periacetabular osteotomy should be performed, particularly for the right acetabulum of this case. However, the indications and timing of these procedures are still a matter of debate. In this case, particularly the right acetabulum with significant dysplasia was observed to have developed and remodeled very well within four years. On 40-year follow-up radiograph, the acetabulum and femur relationship was preserved in both hips and there was no dislocation.

In conclusion, this case has, once again, shown that it should be kept in mind that the hip joint in childhood is a developing joint with remodeling capacity. If acetabulum dysplasia is detected in a hip with concentric reduction between the femoral head and acetabulum, it would be an appropriate approach not to consider surgery immediately and to allow time for acetabulum remodeling. In addition, it is necessary to consider the possibility that femoral osteotomies may be an important treatment option for maintaining the relationship between the acetabulum and the femoral head and maintaining the reduction.

\section{Declaration of conflicting interests}

The authors declared no conflicts of interest with respect to the authorship and/or publication of this article.

\section{Funding}

The authors received no financial support for the research and/or authorship of this article.

\section{REFERENCES}

1. Wang L, Trousdale RT, Ai S, An KN, Dai K, Morrey BF. Dislocation after total hip arthroplasty among patients with developmental dysplasia of the hip. J Arthroplasty 2012;27:764-9.

2. Harsanyi S, Zamborsky R, Krajciova L, Kokavec M, Danisovic L. Developmental dysplasia of the hip: A review of etiopathogenesis, risk factors, and genetic aspects. Medicina (Kaunas) 2020;56:153.

3. Vaquero-Picado A, González-Morán G, Garay EG, Moraleda L. Developmental dysplasia of the hip: Update of management. EFORT Open Rev 2019;4:548-56. 
4. Zhang S, Doudoulakis KJ, Khurwal A, Sarraf KM. Developmental dysplasia of the hip. Br J Hosp Med (Lond) 2020;81:1-8.

5. Murphy RF, Kim YJ. Surgical management of pediatric developmental dysplasia of the hip. J Am Acad Orthop Surg 2016;24:615-24

6. Tomlinson J, O'Dowd D, Fernandes JA. Managing developmental dysplasia of the hip. Indian J Pediatr 2016;83:1275-9.

7. Moraleda L, Bravo C, Forriol F, Albiñana J. Does orientation of the femoral head affect acetabular development? An experimental study in lamb. J Pediatr Orthop 2019;39:416-21.

8. Salter RB, Dubos JP. The first fifteen year's personal experience with innominate osteotomy in the treatment of congenital dislocation and subluxation of the hip. Clin Orthop Relat Res 1974;(98):72-103.

9. Cherney DL, Westin GW. Acetabular development in the infant's dislocated hips. Clin Orthop Relat Res 1989;(242):98-103.

10. Lindstrom JR, Ponseti IV, Wenger DR. Acetabular development after reduction in congenital dislocation of the hip. J Bone Joint Surg [Am] 1979;61:112-8. 